\title{
Analysis on the Phenomenon of Study-Weariness among Chinese
} Applied Undergraduates

\author{
Zeng Hao \\ School of Marxism, Chongqing University of Arts and Science, Yongchuan 402160, Chongqing, China
}

\begin{abstract}
Due to the mutual influence of many factors such as society, schools, teachers, and individual students, there are varying degrees of study weary of students in applied undergraduate universities in China. To solve this problem, it is necessary for authorities to focus on the training goals of applied talents to continue to deepen the reform of applied teaching. Optimizing the structure of the teaching staff through introducing outside, teachers must strive to improve the teaching level and teaching affinity. The daily management of students and ideological work strengthened, students' confidence and determination to "knowledge changes destiny" need building.
\end{abstract}

Keywords: Applied Undergraduate Colleges; Students; Study-Weary

According to the information published on the official website of the Ministry of Education of China, as of June 30, 2020, there are 1,272 general undergraduate colleges and universities in China, most of which are applied for undergraduate colleges and universities ${ }^{[1]}$ Different from the talent training goal of academic universities for cultivating research talents, the objective of talent training is mostly to cultivate application-oriented students suitable for economic and social development. Currently, a series of Student-boring problems occurred in applied undergraduate colleges and universities, which has gradually evolved into a social phenomenon and affected the supply quality of higher education seriously. Therefore, an in-depth analysis of the phenomenon of study weariness in applied undergraduate universities, which is conducted to propose scientific and governments strategies in a targeted manner, will help improve the supply quality of higher education supply and promote the continuous and sustainable development of higher education in China. Go forward healthy.

\section{The daily performance of study weariness in applied undergraduate colleges}

\subsection{Classroom learning}

One is passive learning. Although such students attend classes on time, they are not sufficiently motivated to learn: they do not interact effectively in class. They will not probe for the in-depth exploration of the concepts that the teacher mentioned in the class that they do not understand. Slack off the classwork or research, or even plagiarize others directly. The second is habitual distractions. Despite sitting in the classroom all the way, they often have dull eyes with no vision, namely "physically be somewhere, but be there absent of spirit." The third is repetitive head-downs. Those who bring electronic products such as mobile phones and other books such as novels into the classroom, when the class officially begins, start to fiddle with phones, be absorbed in novels. The fourth is to recurrent makeup of sleep deficit. In class, on account of the lack of interest in the content of the class, poor level of basic knowledge, lack of sleep at night, and other factors, such "desk-buried" students fall asleep as soon as their heads touch the desk. The fifth is what we call constant truancy. Owning the deepest degree of study weariness, these students concentrate on anything but learning, including ignoring the classroom discipline, absence from class, staying in the dormitory, online games addiction, card-playing, and gambling.

\subsection{After-school learning}

One is negativity when it comes to treating after-school learning tasks. Students' self-consciousness is not acute, which leads to the situation where after-school learning tasks designed by the teacher are often treated perfunctorily. The after-school homework, paper materials usually, is often incomplete incoherent, and plagiarized, let alone after-school tasks that cannot be quantified and assessed, such as textbooks and supplementary materials, being often ignored. The second is the lack of effective actions for self-improvement. A considerable number of students in applied undergraduate colleges do not fully realize the gap between themselves and top students. Instead, they take it for granted that time after class is for leisure, which leads to little self-study for further supplementary learning. The third is indulged in things that have nothing to do with learning. The minority have completely 
lost interest in learning. They not only show little concerns about the study, but also be addicted to online games, gambling, dating, and waste a great deal of time and energy on trifles.

\section{Multidimensional inducement of study-weariness in applied undergraduate colleges}

\subsection{Society}

Firstly, the increase of bad temptations in society makes college students gradually addicted. Different from the last century, the development of economy and society has enabled people to entertain and relax in various ways. Bars, Internet cafes, KTV, and other entertainment venues can be seen everywhere near colleges and universities. The temptations faced by contemporary college students are umpteen. At the same time, with the rise and application of the Internet, college students have witnessed the prosperity of Internet derivatives such as online games, online dramas, and live broadcasting. Secondly, the prevalence of negative culture affects college students' learning concepts. With the continuous deepening of China's reform and opening up, people's material living conditions have been greatly improved, and social belief such as hedonism and worship for money has gradually grown and spread among college students in China, resulting in the concept of college students' outlook on life, values, and concentration of study. In addition to the fact that the stratum solidification in Chinese society has formed to a certain extent, the income distribution of some types of work is unreasonable, and the employment quality of graduates from applied undergraduate colleges is relatively poor, the theory of "education is useless" becomes a hit among the students of applied undergraduate colleges.

\subsection{School}

First is the lack of construction in the quality of teaching supply. Most of the current applied undergraduate colleges and universities in China are "upgraded" from junior colleges in this century. Their teachers are relatively weak, and they can be roughly divided into two categories, one is the old teachers who have been teaching in the school in the professional age, and the other is the new "master" and "doctor" after the school "upgraded". Although the elderly teacher has rich teaching experience, they are seriously inadequate in updating their knowledge. The aging of the courses taught is very prominent. Having access to certain frontier technology with theoretical basis and academic vision, newly-employed teachers have insufficient teaching experience. Compared with the established undergraduate colleges, the quantity and quality of curriculum supply in applied undergraduate universities are insufficient, and the quality courses, especially the courses that are popular among students, are even rarer. The second is the insufficient construction of the student evaluation system. Even though most of the current applied undergraduate universities have carried out a series of innovations to the course evaluation methods, the vast majority of courses in the schools still implement the past final exam system. As mentioned earlier, students in applied undergraduate colleges have poor study habits. Under the system of determining whether the course passes the final exam, the so-called "hail 60 points, 1 point is wasted" has become a creed for applied undergraduate college students, who instead of studying hard at usual, choose to cram for the exam, even cheat in the exam. They do not fully understand and master the book knowledge, merely caring about the key content outlined by the teacher before the final exam.

\subsection{Teachers}

Because of the influence of a series of factors such as academic platform, ancillary facilities, quality of students, and location advantages, applied undergraduate universities are relatively less attractive to high-level talent, since their faculty is relatively lower than academic universities and established undergraduate colleges. The wide gap has affected the education and teaching quality of applied undergraduate colleges to a large extent. At the same time, to cater to the current society's evaluation of colleges and universities, and to boost the visibility and social reputation, applied undergraduate colleges and universities have implemented a talent evaluation system that emphasizes scientific research and neglects to teach as teachers and researchers. Under the guidance of this kind of evaluation system, teachers concentrate their main time and energy on scientific research. They usually overlook research teaching as well as teaching problems. Preparing classes and having lectures become side tasks. To make things worse, the lectures are unsurprisingly boring, which ruins students' learning experience.

\subsection{Students}

Under the current Chinese college entrance examination system, the quality of students in applied undergraduate colleges is relatively poor, and their group characteristics mainly include the following three aspects. The first gap is an unsteady professional foundation or insufficient reservation of knowledge. When enrolling students in colleges and universities, the score gap between students is dramatic, the comprehensive reservation of knowledge is being different. The second is the inferior self-discipline ability and the lack of strong will. Compared with the students admitted by the first batch of an undergraduate batch, there is a certain gap in the self discipline and hard working of the applied undergraduate college students. This could also be a major reason for the score difference in the college entrance examination results. The third is inactive learning and lacking of confidence. The failure of the college entrance examination allowed students of applied undergraduate colleges to admit the discrepancies between themselves and top students. While guiding introspection, it also undermined students' self-confidence to an extent. Therefore, in the undergraduate study, students in applied undergraduate colleges often show less confidence in learning, which in turn leads to a series of learning-weariness problems.

\section{Countermeasures to the phenomenon of study-weariness among applied undergraduate college students}

\subsection{Continue to deepen reforms and enhance classroom appeal}

The first is to adhere to the reform of teaching content. It is imperative to focus on the improvement of students' practical 
ability and make necessary adjustments and innovations to the teaching content, by retaining basic theoretical knowledge, delete outdated content uncorrelated with the students' future working practices, and increasing the relevant knowledge needed for students' employment and the frontiers theory in the industry. Simultaneously, it is vital to modify the teaching discourse system by the characteristics of students' weak foundation. Adding to teaching cases, stories, comics, the teaching content is reformed in an interesting way to enhance the appeal of the teaching content to students. The second is to stick to reforming teaching methods. It is the advanced teaching concept that needs introducing, flipped classrooms and bipartition classrooms, to break the ice that the teacher does monodrama for a full class. Diversified teaching approaches, inquiry teaching, simulation teaching, discussion, and debate, for instance, should be adopted to enhance the effective interaction between teachers and students, aiming at an objective that the teaching method of "teacher-guided learning + student independent learning + teacher-student cooperative discussion" informed. It is of great value to adhere to the integration of theory with practice, introduce experiments and cases to traditional classrooms, enable teachers to teach while practising and students would learn while exercising, and facilitate the integration of learning and practising, as well as the unity of knowledge and practice. To adapt to the development course of science and technology, take the initiative to introduce the emerging technologies of cloud classroom and virtual simulation into classroom teaching, enhance students' class experience, and carefully create online and offline hybrid excellent courses. The third is to insist on reforming teaching evaluation methods. The orientation of application-oriented universities not only requires universities to adjust teaching content and teaching methods but also requires reforms in teaching evaluation methods. The key to the change is to enhance the assessment of students' knowledge application ability and break the past rote, which means the final exam to be taken determines whether the course is passed or not. In this regard, pay attention to the teacher-student interaction during normal class, strengthen the process assessment of teaching, scientifically set the content of process assessment, and increase the proportion of the usual grades, half-term grades in the total final grades. In some applied courses, the trial implementation of the final assessment or the inspection system should be used, which combines the solution of practical engineering problems and awards in subject competitions with final results.

\subsection{Adhere to the education orientation and improve the quality of teaching}

The first is to increase the intensity of the introduction and training of masters to create a high-level applied teaching team. It is necessary to increase the introduction of high-level talents and then optimize the academic structure along with the academic structure of the teaching staff. It is urgent to strengthen the fostering and training of teachers in the school, and to boost the teaching level of teachers in a targeted manner through special lectures and teaching competitions. Carry out a collective lesson preparation system for the teaching and research section, taking advantage of collective wisdom and strength to build each professional course, which enables professional course teachers to learn from each other and make progress together. The second is to reform the teacher evaluation system and guide teachers to devote themselves to teaching and educating. It is necessary to change the teacher evaluation orientation of "emphasizing scientific research and neglecting to teach", and erect a set of a teacher evaluation system that pays equal attention to teaching and scientific research. Strengthening examination index functioned as a "baton" to lead teachers to delve into teaching issues and ameliorate teaching skills. Taking advantage of opportunities for faculty, for example, the activity of teaching and research office as well as faculty training, imbued with the educational mission for teachers, so that they should bear in mind that "teacher is the first identity, teaching is the foremost job, and class is the priority responsibility."[2] The third is to further deepen the teaching reform and improve the supply quality of teaching. Teachers should be encouraged to reform classroom teaching content under the cultivation of application-oriented talents, and to enhance the practicality and interest of the courses. Introduce advanced classroom teaching concepts, emphasize the improvement of teaching affinity, and reform the classroom teaching mode or teaching discourse system. It ought to be integrated elements into professional courses while guiding students to build a true learning view along with students' value.

\subsection{Strengthen student management and persevere in ideological guidance}

At present, under the mandatory requirements of the Ministry of Education, China's applied undergraduate universities are equipped with full-time instructors at a teacher-student ratio of not less than 1:200. Counselors are "organizer, implementer, and mentor of the daily ideological and political education and management of college students" and "a life coach and a trusted friend during the adolescent and healthy life of students." ${ }^{[3]}$ It is reasonable to focus on the school's talent training goals to gear up ideological guidance, psychological counseling and daily management of students. First, students' thoughts should be guided and correct learning concepts need building. The construction of style of study is one of the main responsibilities of instructors who are required to stimulate students' interest in learning, lead students to develop good learning habits, and create a dense learning atmosphere, etc.". ${ }^{[4]}$ The students concerning study-weary phenomenon in applied undergraduate colleges and universities shall be grant face-to-face exchange with the instructor, enlightened by positive and negative cases. Under this circumstance, the ideological work of students is to be productive, the negative influence of rumour, "reading is useless," being eradicated. To encourage students to establish the concept that knowledge changes destiny and to consciously resist the bad temptations in society. Second, psychological counseling for students that help build up their confidence in learning is valuable. Self-confidence is the underpinning for success. Concerning the phenomenon of students lacking self-confidence in different degrees, instructors ought to implement responsibilities in three aspects in an orderly way: utilize weekly meetings, internal meetings and other opportunities to provide effective group counseling and guide students face up to the results of the college entrance examination and get rid of the shadow of "I can't make my studies satisfy", and recognize the gaps in order to "repack and start again". It is essential to strengthen the academic tracking of less-advanced students for accurate analysis of what should be blamed for the "slowness" with targeted ideological and psychological counseling. Take an initiative in communication with specialized course teachers, offer to apply positive evaluations in daily learning and life, and inspire students to catch up with their studies. 
Third, maintain daily management of students, and promptly persuade students to learn-weary behavior. Strengthen the instruction and management of students enable instructors to resolve the night-out, playing cards and even gambling, to prevent individual problems from evolving into group phenomena. Establishment of a tutoring system with strict classroom discipline is effective in strictly guarding against discipline-breaking such as being late and absenteeism, and improper behaviors such as playing mobile phones and sleeping during class. Cooperation both online and offline contributed to actively create learning atmosphere that all students catch up with learning and activate students to help each other and make progress together.

\section{References}

1 List of National Colleges and Universities[EB/OL].http://www.moe.gov.cn/jyb_xxgk/s5743/s5744/202007/t20200709_470937. html, 2020-07-09/2020-11-02.

2 2018-2022 The inaugural meeting of the Teaching Steering Committee of the Ministry of Education of Higher Education was held [EB/OL]. http://jyt.shaanxi.gov.cn/jynews/mtsj/201811/02/84171.html, 2018-11- 02/2020-11-02.

3 Ministry of Education of the People's Republic of China. Provisions on the Construction of Counselor Teams in General Higher Education Institutions [Z]. 2017-09-21.

4 Ministry of Education of the People's Republic of China. Provisions on the Construction of Counselor Teams in General Higher Education Institutions [Z]. 2017-09-21. 